\title{
Preface: The 10th International Carbon Dioxide Conference (ICDC10) and the 19th WMO/IAEA Meeting on Carbon Dioxide, Other Greenhouse Gases, and Related Measurement Techniques (GGMT-2017)
}

\author{
Fortunat Joos ${ }^{1}$ and Brigitte Buchmann ${ }^{2}$ \\ ${ }^{1}$ Climate and Environmental Physics, Physics Institute and Oeschger Center for Climate Change Research, \\ University of Bern, Sidlerstr. 5, 3012 Bern, Switzerland \\ ${ }^{2}$ Empa, Materials Science and Technology, Überlandstrasse 129, 8600 Dübendorf, Switzerland
}

Correspondence: Fortunat Joos (joos@ climate.unibe.ch)

Published: 4 June 2018

Understanding the atmospheric concentrations of carbon dioxide $\left(\mathrm{CO}_{2}\right)$ and other greenhouse gases is a relevant and extremely topical research area. On the one hand, the complex natural cycles of these gases, their fascinating past variations, and their massive perturbations by humans pose interesting research questions and a need for curiosity-driven ongoing investigations. One the other hand, anthropogenic emissions of $\mathrm{CO}_{2}$ and other greenhouse gases perturb the climate with far-reaching consequences for natural and socioeconomic systems. This calls for comprehensive research studies to provide relevant, solution-oriented scientific findings to policymakers. The parties of the Paris Agreement, recognizing the threat of dangerous anthropogenic climate interferences, agreed (i) to limit global warming to maximum $2{ }^{\circ} \mathrm{C}$ and (ii) "to achieve a balance between anthropogenic emissions by sources and removals by sinks of greenhouse gases in the second half of this century".

The major greenhouse gas sources and sinks are reasonably well understood. It is also clear that $\mathrm{CO}_{2}$ emissions from fossil energy use is the dominant driver of humancaused global warming. A significant fraction of these emissions will stay in the atmosphere over many millennia; warm the lower atmosphere and the ocean; and aggravate observed ocean acidification, ocean deoxygenation, and sea level rise. However, in the details there remain many open questions. Which processes led to past abrupt shifts and glacial-interglacial variations in greenhouse gas concentrations, and may similar abrupt shifts happen in the future? What are the drivers of greenhouse gas sources and sinks, and how will the sinks evolve in the future? What observational systems are to be in place to verify reported country-based emission reductions? How can we refine the art of measuring greenhouse gases? What can we learn from carbon isotopes? How will more frequent and severe extreme events such as marine and atmospheric heat waves affect the carbon cycle? How does global warming drive emissions of carbon dioxide, methane, and nitrous oxide from natural ecosystems such as peat- and wetlands? How will land management by humans affect greenhouse gas emissions? What are the options to limit and reduce human perturbations of the Earth system?

Two conference series - the International Carbon Dioxide Conference (ICDC) and the Carbon Dioxide, Other Greenhouse Gases, and Related Measurement Techniques Conference (GGMT) - provide the interdisciplinary platform to discuss these and related questions. ICDC returned for its anniversary event to its origin, the Bernese area in Switzerland. The first two events of the quadrennial conference series were organized in 1981 in Bern and in 1985 in the village of Kandersteg by Hans Oeschger, Charles David Keeling, and Ulrich Siegenthaler. Meanwhile the seeds of these pioneers in the fields of ice core $\mathrm{CO}_{2}$ reconstructions, atmospheric $\mathrm{CO}_{2}$ measurements, and carbon cycle modeling have matured. The conference has developed into an established platform for the global scientific community for the exchange of the latest scientific results and for the initiation of new collaborations. The conference provides an integrated, interdisciplinary view of the global carbon cycle and 
its perturbation by humans. Conference themes include the contemporary carbon cycle, its trends, variability, and observations; the paleo-perspective and planetary boundaries; biogeochemical processes and their feedbacks and linkages with ecosystems as well as climate and socioeconomic processes; scenarios for the future and steps toward long-term Earth system stability; and carbon cycle research in support of the Paris Agreement.

GGMT started in 1975 as a $\mathrm{CO}_{2}$ experts meeting initiated by Charles David Keeling together with only a few experts. Nowadays organized in 2-year intervals at various locations around the globe, the GGMT conferences have become cornerstone events of the international greenhouse gas monitoring and research programs. The World Meteorological Organization (WMO) provided the umbrella to all GGMT meetings, and in 1997 the International Atomic Energy Agency (IAEA) in Vienna joined. The latest scientific findings are exchanged with respect to measurement techniques and calibration strategies, urban network development and megacities, comparison of reference materials, remote sensing and integration of observations, and data products and policy. Target species are carbon dioxide and other greenhouse gases, stable isotopes, and radiocarbon in greenhouse gas measurements. Thus, GGMT serves as the scientific backbone of the observation programs of the WMO, supporting worldwide compatibility of observations relevant for scientists, policymakers, and international treaties.

ICDC10 (www.icdc10.ch, last access: 28 May 2018) took place in Interlaken, Switzerland during 21-25 August 2017 and was hosted by the Oeschger Center for Climate Change Research, University of Bern. Contributions were invited from natural and social scientists and from all disciplines addressing the global carbon cycle and its anthropogenic perturbation. ICDC10 was attended by 520 participants from all inhabited continents. Seven out of the 15 invited oral presentations were given by female scientists. Thirty-four oral presentations in plenary and 48 in parallel sessions were complemented by 374 poster presentations. Special sessions were dedicated to our esteemed late colleagues Ernst MaierReimer and Michael R. Raupach.

The 19th GGMT (GGMT-2017; www.empa.ch/ggmt2017, last access: 28 May 2018) conference was organized and hosted by Empa in Dübendorf from 27 to 31 August 2017. One hundred sixty-eight participants from 26 countries and 6 continents attended the conference. One hundred seventeen abstracts were submitted prior to the meeting, and the advisory committee selected 47 and 70 abstracts for oral and poster presentations, respectively.

This special issue presents written contributions from ICDC10 and GGMT-2017. The special issue is open access and jointly organized between the journals Atmospheric Measurement Techniques, Atmospheric Chemistry and Physics, Biogeosciences, Climate of the Past, and Earth System Dynamics. The papers of the two conferences significantly contribute to the understanding of our Earth sys- tem by improving observational capabilities and by exploring and quantifying mechanisms, variability, and human-induced change. The findings provide relevant information to establish the best scientific knowledge on pressing scientific, environmental, and societal challenges.

Acknowledgements. We would like to thank the authors for their contributions to the conference and this special issue, the editors for handling the manuscripts, and the scientific steering committees for their guidance in establishing the scientific programs of ICDC10 and GGMT-2017. We are grateful for the support received by the local organizing committees and the many helpers to make the two conferences memorable events.

The ICDC10 organizers thank the following institutions for sponsorship: the Intergovernmental Panel on Climate Change (IPCC), the World Climate Research Programme (WCRP), Future Earth, the Global Carbon Project (GCP), the Global Land Project (GLP), the High Altitude Research Stations Jungfraujoch \& Gornergrat (HFSJG), the Integrated Marine Biogeochemistry and Ecosystem Research (IMBER), the International Ocean Carbon Coordination Project (IOCCP), the International Space Science Institute (ISSI), the Ocean Acidification International Coordination Centre/International Atomic Energy Agency (OA_ICC, IAEA), Past Global Changes (PAGES), the Forum for Climate and Global Change of the Swiss Academy of Sciences (ProCLIM), and the Surface Ocean Lower Atmosphere Study (SOLAS). The ICDC10 organizers are grateful for financial support by the Swiss Federal Office for the Environment; the cogito foundation; Lotteriefonds des Kantons Bern; the Swiss Academy of Sciences - Commission on Atmospheric Chemistry and Physics; the Federal Office of Meteorology and Climatology (MeteoSwiss); Fondation Johanna DürmüllerBol; the Swiss National Science Foundation; the Center for Climate Systems Modelling, ETH Zürich; GVB Kulturstiftung; OAICC, IAEA: Ocean Acidification International Coordination Centre - International Atomic Energy Agency; and the International Space Science Institute. ICDC10 thanks Gerber project management for outstanding organizational support and the Congress Centre Interlaken for providing a stimulating and pleasant conference environment.

The GGMT organizers thank the following institutions for their support and sponsorship: WMO, IAEA, MeteoSwiss, the Federal Office for the Environment (FOEN), the Commission on Atmospheric Chemistry and Physics (ACP) of the Swiss Academy of Sciences (SCNAT), and HFSJG. In addition, the event was supported by the following corporate sponsors: Ecotech, ABB Inc.-Los Gatos Research, Mirico, Decentlab, Air Liquide, Aerodyne Research, LICOR, and Picarro. 